\title{
The Effect of the Operational Parameters on the Draft Requirement of Ripping in a Sandy Clay Soil
}

\author{
John Ndisya*, Ayub Gitau, Duncan Mbuge, Angela Hiuhu \\ Department of Environmental \& Biosystems Engineering, University of Nairobi, Nairobi, Kenya \\ Email: "mulwa88@gmail.com
}

Received 23 November 2015; accepted 29 February 2016; published 3 March 2016

Copyright (C) 2016 by authors and Scientific Research Publishing Inc.

This work is licensed under the Creative Commons Attribution International License (CC BY). http://creativecommons.org/licenses/by/4.0/

(c) (i) Open Access

\section{Abstract}

This study set out to investigate the effect of operational parameters (i.e. ripping depth and operational speed) during a ripping operation on the draft requirement during ripping in a sandy-clay soil. Field experiments, laboratory tests and numerical modelling techniques were utilised to observe how the draft force varied with changing values of the operational parameters. The discrete element method in the EDEM Academic ${ }^{\mathrm{TM}}$ software platform was employed to model the soil en-masse to obtain a virtual experimentation platform on which different treatments combing different settings of the operational parameters were investigated. Statistical methods, including ANOVA, regression analysis and the student t-test were applied to establish the significance of the effect of the operational parameters on the draft requirement; statistical analysis revealed that the draft increased linearly with the ripping depth and operating speed suggesting that they are directly proportional. Lower values of the ripping depth and operating speed were found to give the minimum amount of the draft requirement.

\section{Keywords}

Draft Requirement, Discrete Element Method, Numerical Simulation, Specific Draft, Ripping Depth, Operational Speed

\section{Introduction}

In any agricultural set-up, soil compaction has been shown to reduce crop productivity [1]; this is chiefly due to the reduction of the infiltration capacity of the upper and mid-level soil layers. Several years of research have

\footnotetext{
${ }^{*}$ Corresponding author.
}

How to cite this paper: Ndisya, J., Gitau, A., Mbuge, D. and Hiuhu, A. (2016) The Effect of the Operational Parameters on the Draft Requirement of Ripping in a Sandy Clay Soil. Open Journal of Optimization, 5, 1-13. 
shown soil compaction to be caused by various factors including farm machinery wheel traffic, conventional agriculture practises that include elimination of crop residue by grazing animals prior to cultivation and the plough sole caused by tilling at the same depth using the mouldboard plough.

To overcome the challenges posed by the conventional tillage practises, conservation agriculture was developed; this new system of agriculture is characterised by a permanent soil cover composed of vegetative material from the previous crop, weed control by the use of chemicals and land preparation by methods that disturb neither the soil nor the vegetative cover. The main advantage of the conservation method of agriculture is that it leads to the conservation of soil, water and energy; while conservation agriculture has been touted to create a win-win situation where conservation is practised while still benefiting the farmer, conventional tillage practises are still very popular around the world; thus ripping is still practised to break compacted soil layers in many farms.

With the increase in the prices of fossil fuels that has been experienced in the past several years, there is a need to make conventional tillage more energy efficient in order to sustain acceptable profit margins [2]. The energy efficiency of a tillage tool is a function of its design, soil properties and the mode of operation; tillage factors for ripping such as the ripping depth and the speed of the operation thus significantly influence the energy dissipated in the ripping operation. While it is not entirely possible to control the soil properties for an optimal operation; operational factors, besides being constrained by the timeliness factor, can be optimised to achieve energy efficiency.

Recent advancements in technology, particularly the improvement of computing power, have provided a good platform on which tillage research can be conducted; tillage tools can now be conveniently designed and tested in a virtual environment to cut down or even entirely eliminate the time and costs incurred by utilising classical methods; there is now no need to design and test tools by prototype testing alone. This study utilised the discrete element method and the EDEM Academic ${ }^{\mathrm{TM}}$ software to investigate the effect of the ripping depth and operating speed on the draft requirement of a ripping operation.

\section{Materials and Methods}

\subsection{Description of the Study Area}

This study was carried out in the University of Nairobi Field Station at Upper Kabete in a farm lying $1^{\circ} 15$ 'S and $36^{\circ} 44^{\prime} \mathrm{E}$ at an altitude of about 1940 meters above sea level.

The soil at the site is a humic nitisol [3] and the climate of the area is characterized by average temperatures of between $26.8^{\circ} \mathrm{C}$ during the warmest month and $9.1^{\circ} \mathrm{C}$ during the coldest month as recorded at the nearby Kabete Observation Station; the average annual rainfall is about $1100 \mathrm{~mm}$ as typical of the central Kenyan highlands.

\subsection{Data Collection Approach}

\subsubsection{Experimental Set-Up}

Field investigations involved conducting field ripping trials where the draft data was recorded using a data logging station consisting of an MSI7300 digital dynamometer and the MSI8000 handheld remote display connected to a stationary laptop computer. The MSI7300 digital dynamometer was connected between two Massey Ferguson tractors using chains and steel shackles since it could not be connected directly to the three-point hitch of any tractor; the arrangement is as shown in Figure 1 and Plate 1 . The ripper tine utilised in the field investigations was connected to the tool carriage which was in-turn connected to the three point hutch of the rear towed tractor.

Pre-trial runs were conducted before the main runs to establish the rolling resistance of the towed tractor and the tool carriage; this value was later subtracted from the measured draft force to obtain a net value of the measurements.

\subsubsection{Experimental Design}

This study utilised a $5 \mathrm{~cm}$ wide ripper tines of rake angles of $30^{\circ}, 45^{\circ}, 60^{\circ}$ and $75^{\circ}$ and a length of $50 \mathrm{~cm}$ as shown in Figure 2; the ripping depth was in three levels (i.e. 15, 25 and $40 \mathrm{~cm}$ ) while the operating speed was in two levels (i.e. 3 and $5 \mathrm{~km} / \mathrm{hr}$ ); these parameters were combined into a 2 by 3 factorial experiment in a completely randomized design with 4 replications to a give a total of 24 exclusive treatments. 


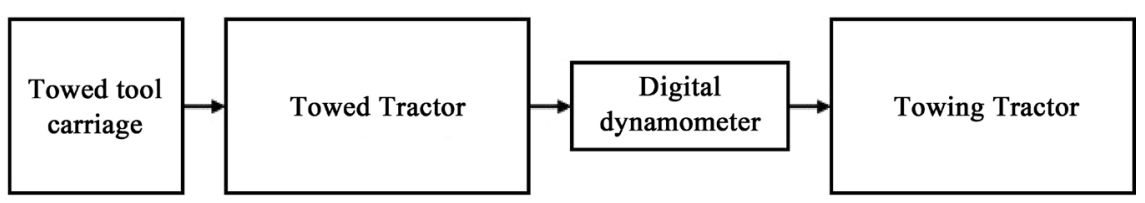

Figure 1. The experimental set-up.
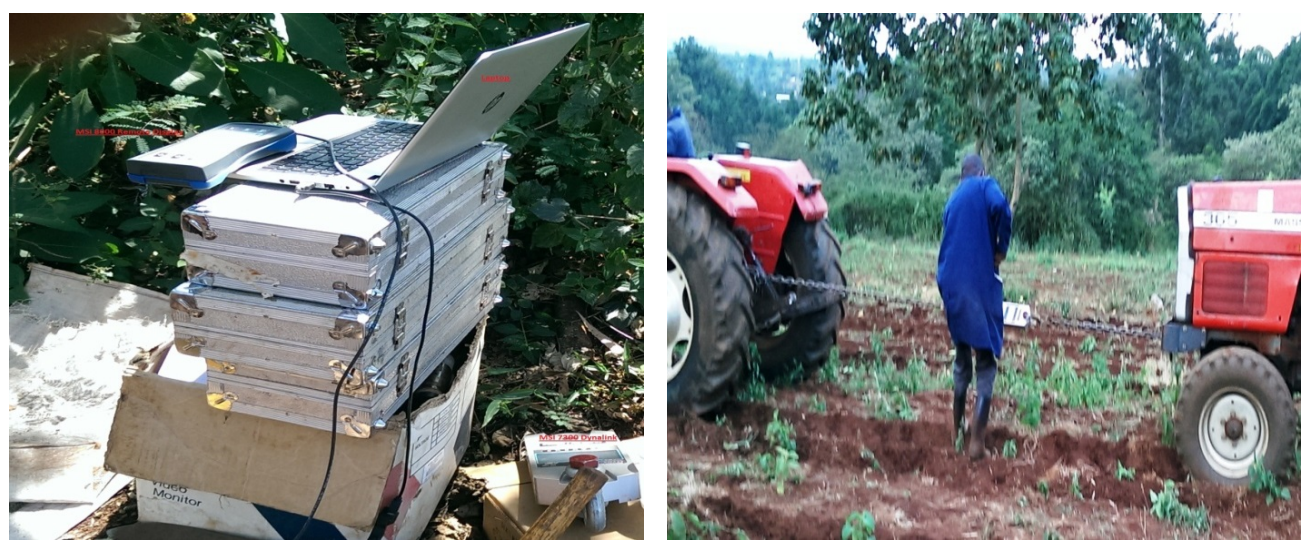

Plate 1. Field data logging station setup.

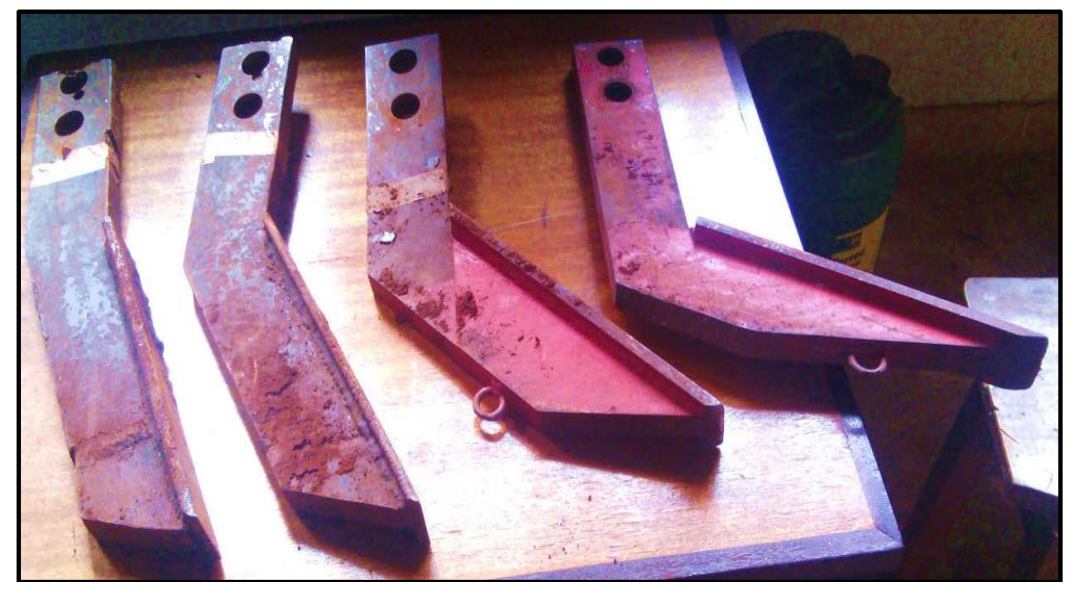

Figure 2. The Ripper tines used.

Randomization was conducted by assigning alphanumeric codes written onto pieces of paper and placed in a box to the various treatments and choosing a treatment at random without replacement to be executed; experiments were conducted in the actual order in which their codes were drawn from the box.

\subsubsection{Soil Data-Sets Collected}

Soil samples were collected during field investigations to characterise the site soil condition; the samples were analysed in the soils laboratory to establish the shear strength parameters (i.e. cohesion, angle of internal friction), moisture content, angle of repose, particle shape and size distribution, bulk density and cone index.

\subsubsection{Computer Simulation}

A numerical simulation model was developed with EDEM Academic ${ }^{\mathrm{TM}}$ software and calibrated by modeling the angle of repose test to investigate the effects of the operational parameters on the draft requirement; a set of calibration parameters that gave the optimal values of the surface energy value, coefficient of static friction, coefficient of rolling friction and the coefficient of restitution were established during a batch simulation operation in EDEM Academic ${ }^{\mathrm{TM}}$ and used to conduct the full-scale simulation runs. Simulation results were exported from 
EDEM Academic ${ }^{\mathrm{TM}}$ using the query feature in a comma separated format to Microsoft Excel and SPSS for cleaning and analysis.

\subsubsection{Statistical Analysis}

The following statistical operations were conducted in Microsoft Excel and SPSS.

1) Any outliers in the measured data were eliminated by taking the median value of the data streams.

2) The One Sample Kolmogorov-Smirnov Test in SPSS was performed on both the measured and predicted data to establish their probability distribution to facilitate the subsequent statistical operations.

3) ANOVA was applied to test whether the treatments (i.e. differences in ripping depths and operating speeds) had an effect on the specific draft.

4) The student t-test was applied to test whether the mean of the measured specific draft was significantly similar or different from the mean of the predicted specific draft.

5) Regression analysis was conducted to evaluate the relationship between the measured specific draft and the predicted specific draft.

\section{Results and Discussions}

\subsection{Experimental Site Soil Characteristics}

Laboratory analysis was conducted on the soil samples collected during field investigations; the soil was classified to be a sandy-clay exhibiting a dry density of $1818 \mathrm{~kg} / \mathrm{m}^{3}$, an angle of repose of $34^{\circ}$ and a cone index of $220.56 \mathrm{kpa}$ at the experimental moisture content of $19 \%$.

\subsection{Rolling Resistance}

The rolling resistance was established during field investigations by recording several data points using the digital dynamometer; since the data points varied significantly due to the periodic instability of the experimental set-up, the median of the data points was computed to be $1.07 \mathrm{kN}$; this was the value used as the rolling resistance; this value was subtracted from the measured draft data to obtain the net draft which was then divided by the width of the ripper tine (i.e. $5 \mathrm{~cm}$ ) to obtain the specific draft force datasets.

\subsection{Development of the Numerical Model and Simulation}

Numerical simulation of the ripping process was conducted by developing a model in EDEM Academic ${ }^{\mathrm{TM}}$ ver- $^{-}$ sion 2.7.0 running on a Toshiba Qosmio ${ }^{\circledR}$ Laptop with an i7 processor (2.64 Ghz Quad core), RAM of 8 GB, storage space of $1 \mathrm{~TB}$ and a 64-bit Windows 7 Operating System.

\subsubsection{Main Settings}

The main settings in EDEM Academic ${ }^{\mathrm{TM}}$ involved changing the platform's units to SI in the main window; the other settings are provided in Table 1.

\subsubsection{Particle Modeling}

The soil particle shapes generalized using optimal imaging techniques were remodeled in EDEM Academic ${ }^{\mathrm{TM}}$ as

\begin{tabular}{ccc} 
Table 1. Global settings in EDEM Academic & & \\
\hline PM & & \\
\hline Pork function & Units & Value \\
Gravity & $\mathrm{eV}$ & 0 \\
Poisson's ratio of steel & $\mathrm{m} / \mathrm{s}^{2}$ & -9.81 \\
Shear modulus of steel & No units & 0.3 \\
Density of steel & Pascals & $7 \times 10^{10}$ \\
Poisson's ratio of soil & $\mathrm{kg} / \mathrm{m}^{3}$ & 7850 \\
Shear modulus of soil & No units & 0.25 \\
Density of soil & Pascals & $1 \times 10^{7}$ \\
& $\mathrm{~kg} / \mathrm{m}^{3}$ & 1818 \\
\hline
\end{tabular}


an assemblage of three spheres to achieve the target soil shape and size as described in Figure 3 and Figure 4.

\subsubsection{Simulation Geometries}

A particle factory plate and a virtual soil-bin were created using EDEM Academic ${ }^{\mathrm{TM}}$ inbuilt modeling capabilities to generate particles and hold the modeled soil particles that would be generated during the simulation process. The ripper tine was also remodeled in AutoCAD and imported into EDEM Academic ${ }^{\mathrm{TM}}$ using the inbuilt CAD import tool. These simulation geometries are provided in Figure 5, Figure 6 and Figure 7.

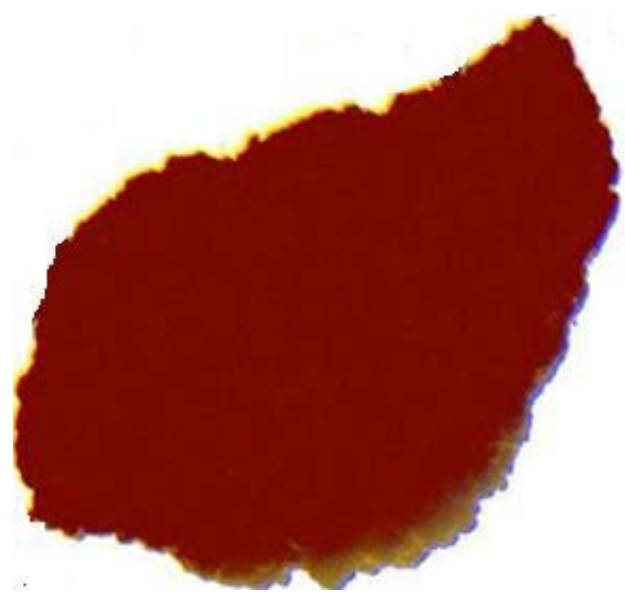

Figure 3. Soil particle to be remodeled.

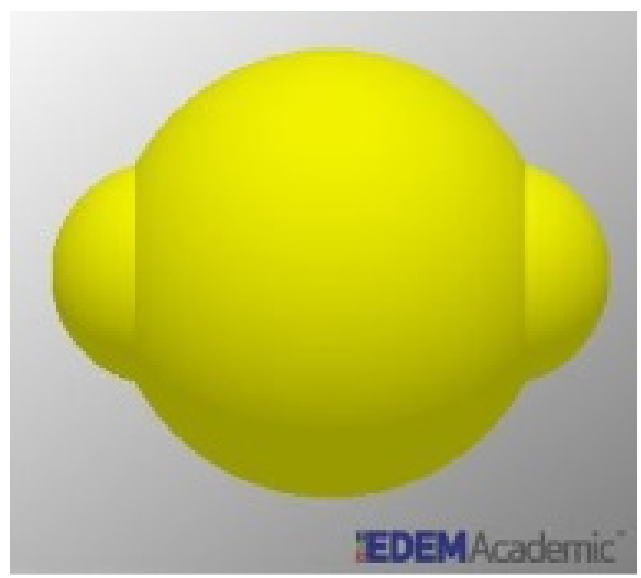

Figure 4. Remodeled soil particle ${ }^{\circledR}$.

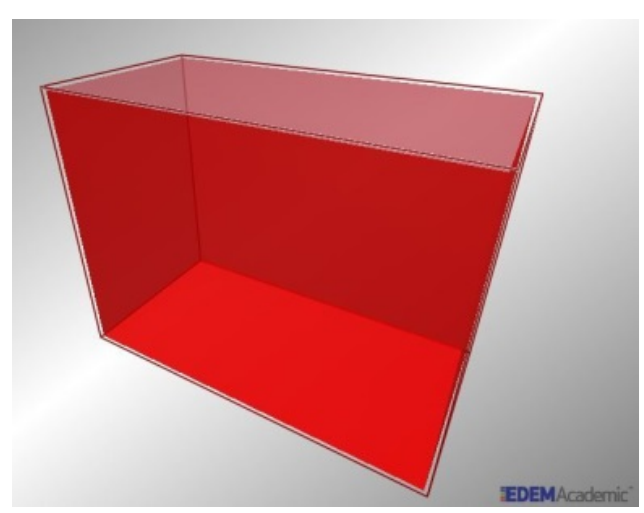

Figure 5. Empty virtual box ${ }^{\circledR}$. 


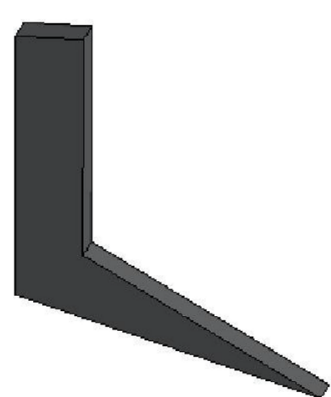

$30^{\circ}$ Ripper Tine

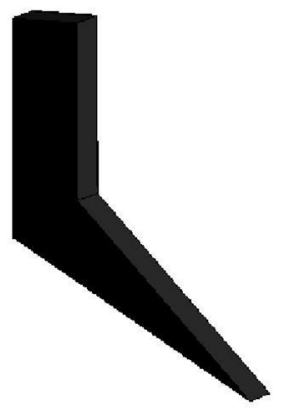

$45^{\circ}$ Ripper Tine

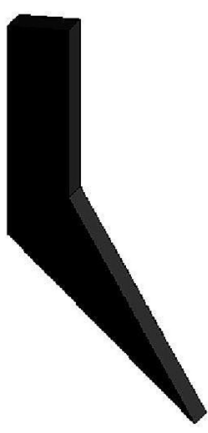

$60^{\circ}$ Ripper Tine

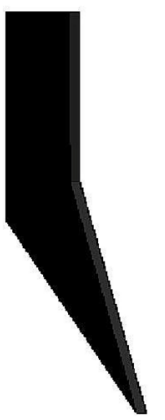

$75^{\circ}$ Ripper Tine

Figure 6. The ripper tines remodeled in AutoCAD.

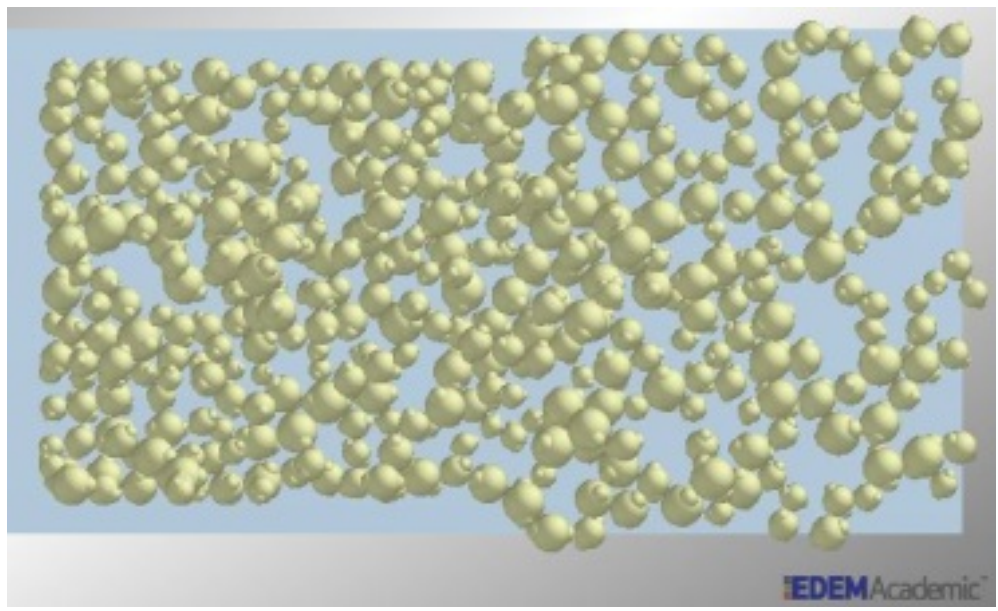

Figure 7. Particles dropping from the particle factory ${ }^{\circledR}$.

\subsubsection{Particle Factory and Simulator Settings}

Particle creation settings were specified in the created factory plate to create simulation particles at a rate of 4000 particles per second until the virtual soil-bin was filled to the brim. The particles were set to be distributed in a log-normal manner with a mean of 0.7769 and a standard deviation of 1.82261 and to be placed randomly in the virtual soil-bin at a velocity of $20 \mathrm{~m} / \mathrm{s}$. The time-step for the simulation was set at $20 \%$ of the Raleigh time step and to run for 15 seconds with a target save interval of 0.1 seconds.

\subsubsection{Model Calibration and Full Scale Simulation Runs}

The angle of repose test was performed on the physical en-masse material as shown in Figure 8 to provide the optimal calibration values for the model; the model was then calibrated by conducting a batch simulation operation iteratively to establish the surface energy value, coefficient of static friction, coefficient of rolling friction and the coefficient of restitution that constrained the materials to give a similar angle of repose as the physical test.

The optimal values of the calibration parameters that gave an angle of repose close to the physical test are given in Table 2; the simulation model was then set to be executed at such values.

\subsection{Statistical Analysis of the Draft Data}

The measured and the predicted specific draft data were subjected to the One Sample Kolmogorov-Smirnov Test in SPSS to investigate whether they were normally distributed; this was a vital operation since the subsequent ANOVA, regression analysis and the student t-test operations would be conducted with the assumption that the data was normally distributed. The p-values for both datasets were found to be greater than 0.05 at the $95 \%$ level of confidence; this indicated that the null hypothesis that the datasets were normally distributed was true. 


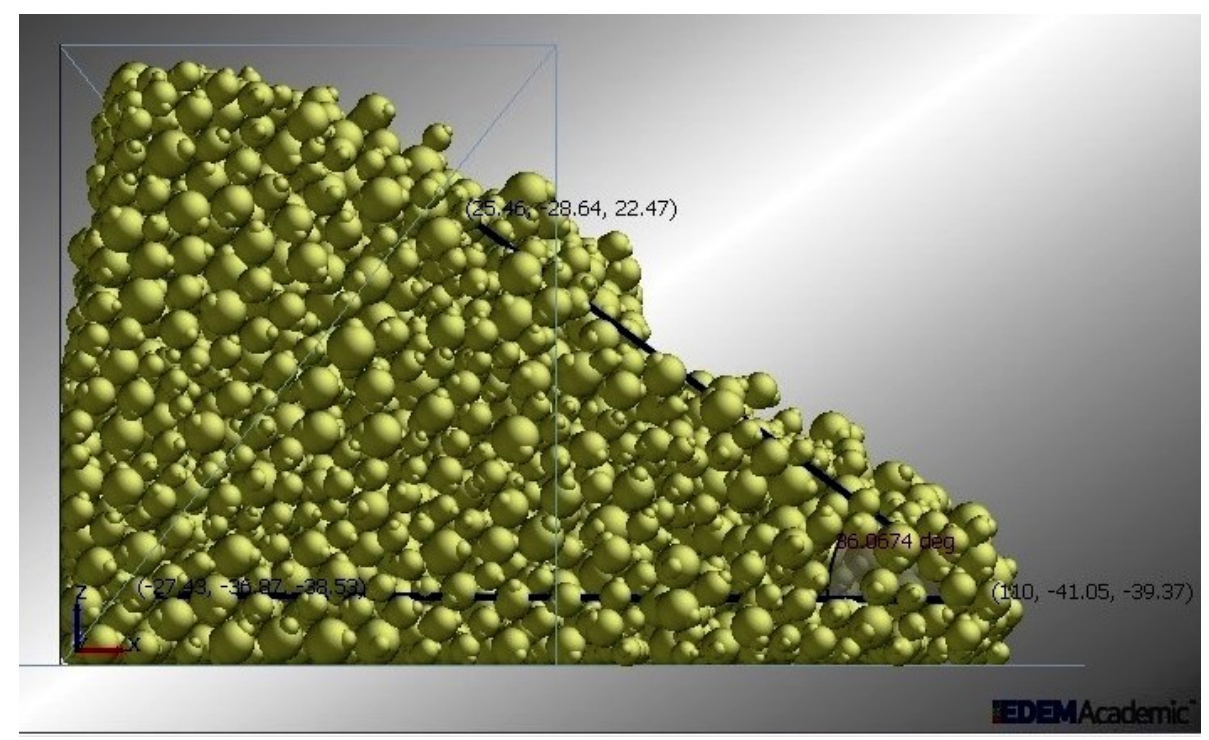

Figure 8. Slumped soil mass in EDEM Academic ${ }^{\mathrm{TM}}$ showing the angle of repose.

Table 2. Calibration parameter settings for the numerical model.

\begin{tabular}{cc}
\hline Parameter & Value \\
\hline JKR surface energy $\left(\mathrm{J} / \mathrm{m}^{2}\right)$ & 5 \\
Coefficient of restitution & 0.2 \\
Coefficient of static friction & 0.4 \\
Coefficient of rolling friction & 0.06 \\
Angle of repose (EDEM Academic $\left.{ }^{\mathrm{TM}}\right)$ & $33.6^{\circ}$ \\
Angle of repose (physical test) & $34^{\circ}$
\end{tabular}

Regression analysis was performed on the measured and the predicted specific draft data to investigate their degree of fit; the results of regression, as shown in Figure 9, confirmed the findings of the paired samples t-test that there was sufficient evidence to the cause that the measured specific draft was similar to the predicted specific draft; the coefficient of determination $\left(\mathrm{R}^{2}\right)$ was 0.986 indicating an high degree of fit; this implied that the developed model truly reflected the actual ripping operation in a sandy-clay soil. The predicted specific draft data was then used to establish the effect of the operational parameters on the draft requirement in a sandy-clay soil.

The predicted specific draft datasets were reordered and subjected to ANOVA in SPSS with the predicted specific draft as the dependent variable and the ripping depth and operating speed as the factors. The p-values for the ripping depth and operating speed were all found to be greater than 0.05 at the $95 \%$ level of confidence; the alternative hypothesis that both parameters significantly influenced the specific draft was accepted.

\subsection{The Influence of Operational Parameters on the Draft Force}

\subsubsection{Effect of Ripping Depth}

[4] emphasized the significance of the working depth in any tillage operation. In their studies, they discovered that the draft values of all reference tillage tools and hence, scale-model/prototype implements were found to be primarily dependent on depth of operation.

This study established that the draft increased in a near linear manner with increase in the tillage depth; this indicated that the draft force was directly proportional to the tillage depth. The measured specific draft values at the two levels of speed converged at ripping depths less than $25 \mathrm{~cm}$; this could be due to the presence of a loose layer of soil above the $25 \mathrm{~cm}$ depth that gave similar draft force values regardless of the operating speed; the difference was however more pronounced for the predicted specific draft values. 
At the rake angle of 30 degrees, this study found both the measured and predicted specific draft to increase in a linear manner with the ripping depth as shown in Figure 10. Increasing the ripping depth from $15 \mathrm{~cm}$ to about $40 \mathrm{~cm}$ resulted to an increase in the specific draft by $1.33 \mathrm{kN} / \mathrm{cm}$ at the speed of $3 \mathrm{kph}$ and by $2.15 \mathrm{kN} / \mathrm{cm}$ at the speed of $5 \mathrm{kph}$.

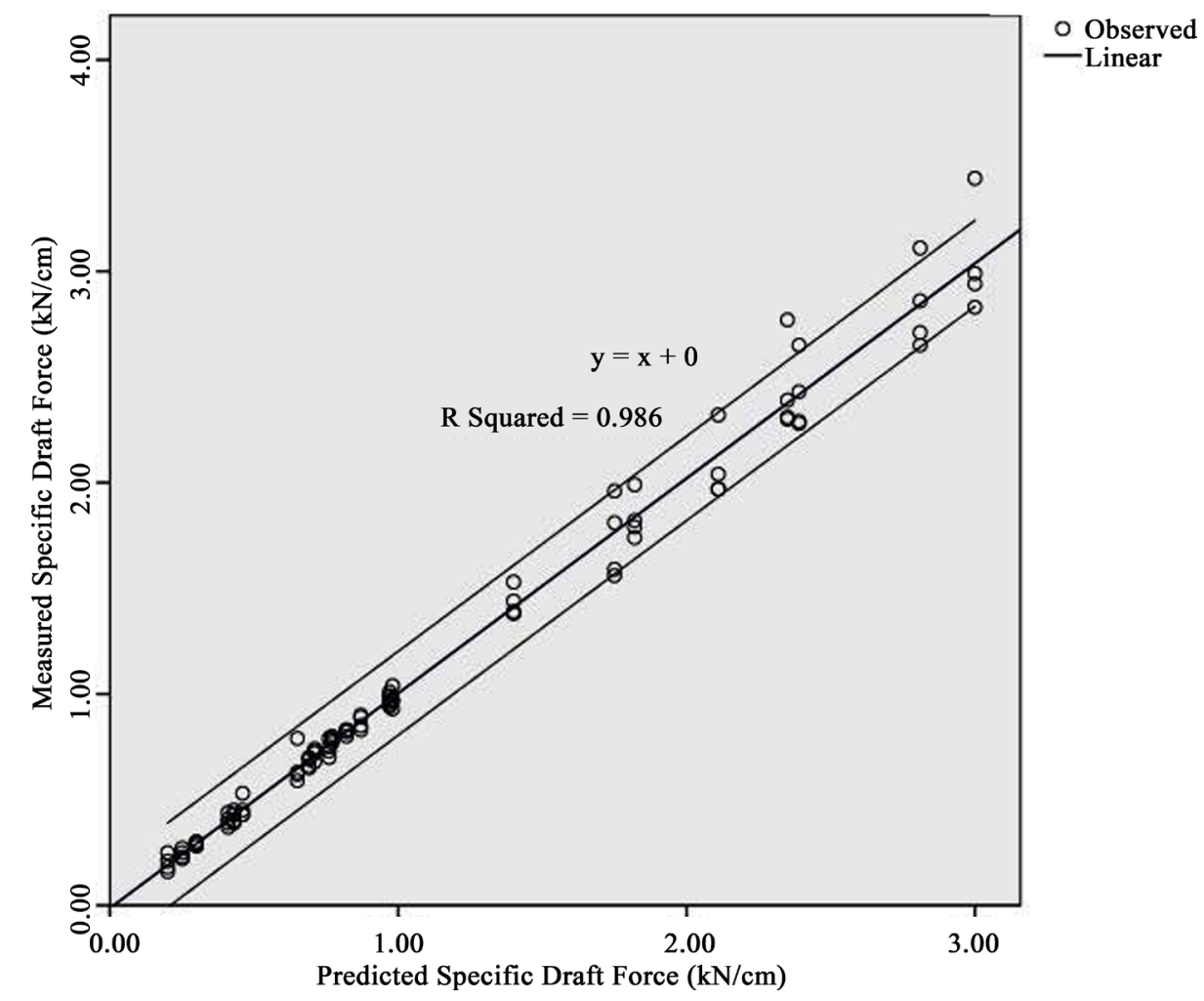

Figure 9. Linear regression between measured and predicted specific draft force.

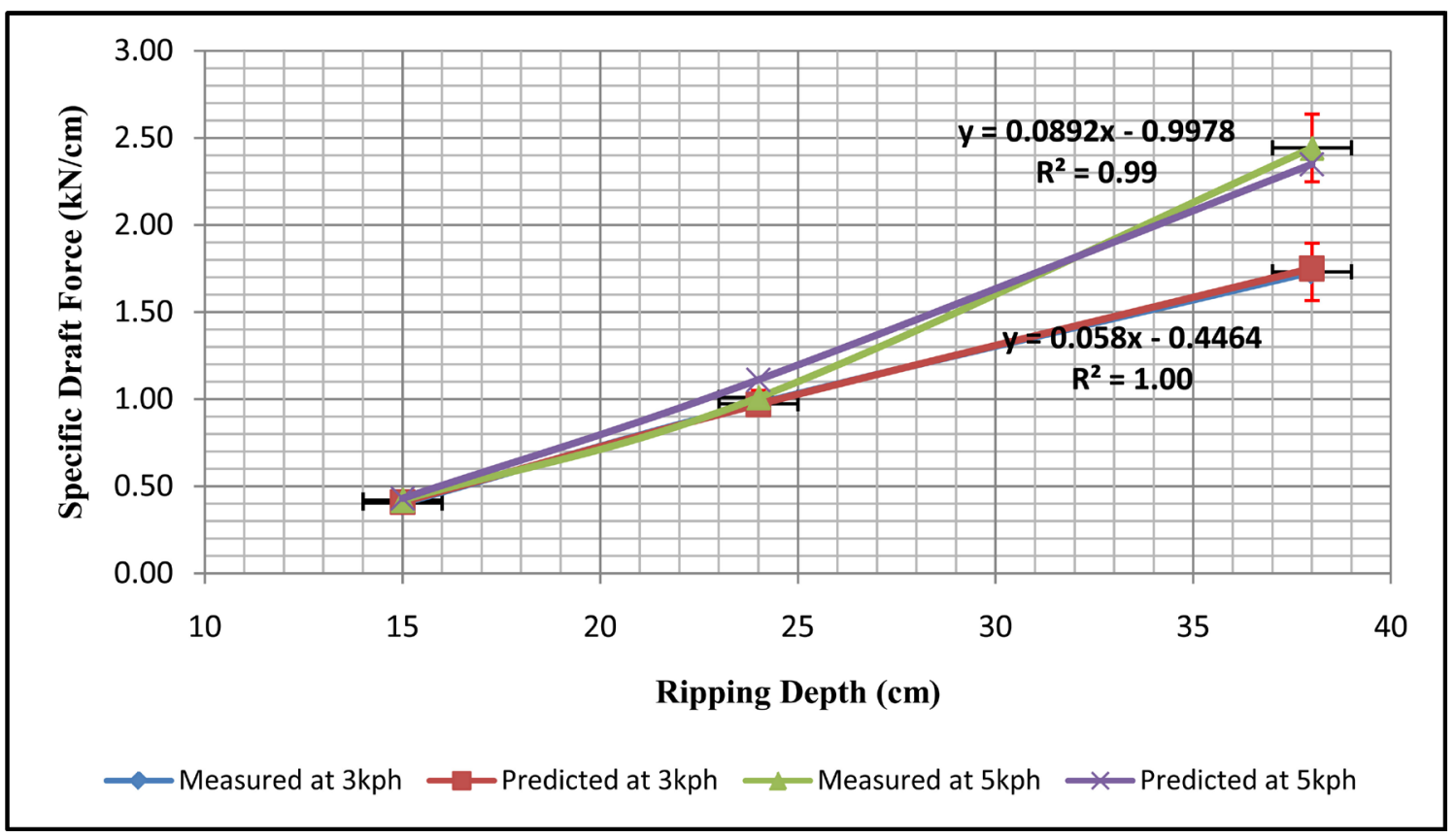

Figure 10. Specific draft force against ripping depth at a rake angle of $30^{\circ}$. 
At the rake angle of 45 degrees, the measured and predicted specific draft increased linearly with the ripping depth as shown in Figure 11. Increasing the ripping depth from $15 \mathrm{~cm}$ to about $40 \mathrm{~cm}$ resulted to an increase in the specific draft by $1.23 \mathrm{kN} / \mathrm{cm}$ at the speed of $3 \mathrm{kph}$ and by $1.59 \mathrm{kN} / \mathrm{cm}$ at the speed of $5 \mathrm{kph}$.

At the rake angle of 60 degrees, the measured and predicted specific draft increased linearly with the ripping depth as shown in Figure 12. Increasing the ripping depth from $15 \mathrm{~cm}$ to about $40 \mathrm{~cm}$ resulted to an increase in the specific draft by $1.66 \mathrm{kN} / \mathrm{cm}$ at the speed of $3 \mathrm{kph}$ and by $2.37 \mathrm{kN} / \mathrm{cm}$ at the speed of $5 \mathrm{kph}$.

At the rake angle of 75 degrees, the measured and predicted specific draft increased linearly with the ripping depth as shown in Figure 13. Increasing the ripping depth from $15 \mathrm{~cm}$ to about $40 \mathrm{~cm}$ resulted to an increase in the specific draft by $1.7 \mathrm{kN} / \mathrm{cm}$ at the speed of $3 \mathrm{kph}$ and by $2.4 \mathrm{kN} / \mathrm{cm}$ at the speed of $5 \mathrm{kph}$.

The draft has been shown to increase with an increase with the ripping depth; in his research to develop models for chisel plows using Artificial Neural Networks working with different soil conditions, [5] found the draft to increase in a linear manner with the working depth. This was in agreement with the findings of [6] who

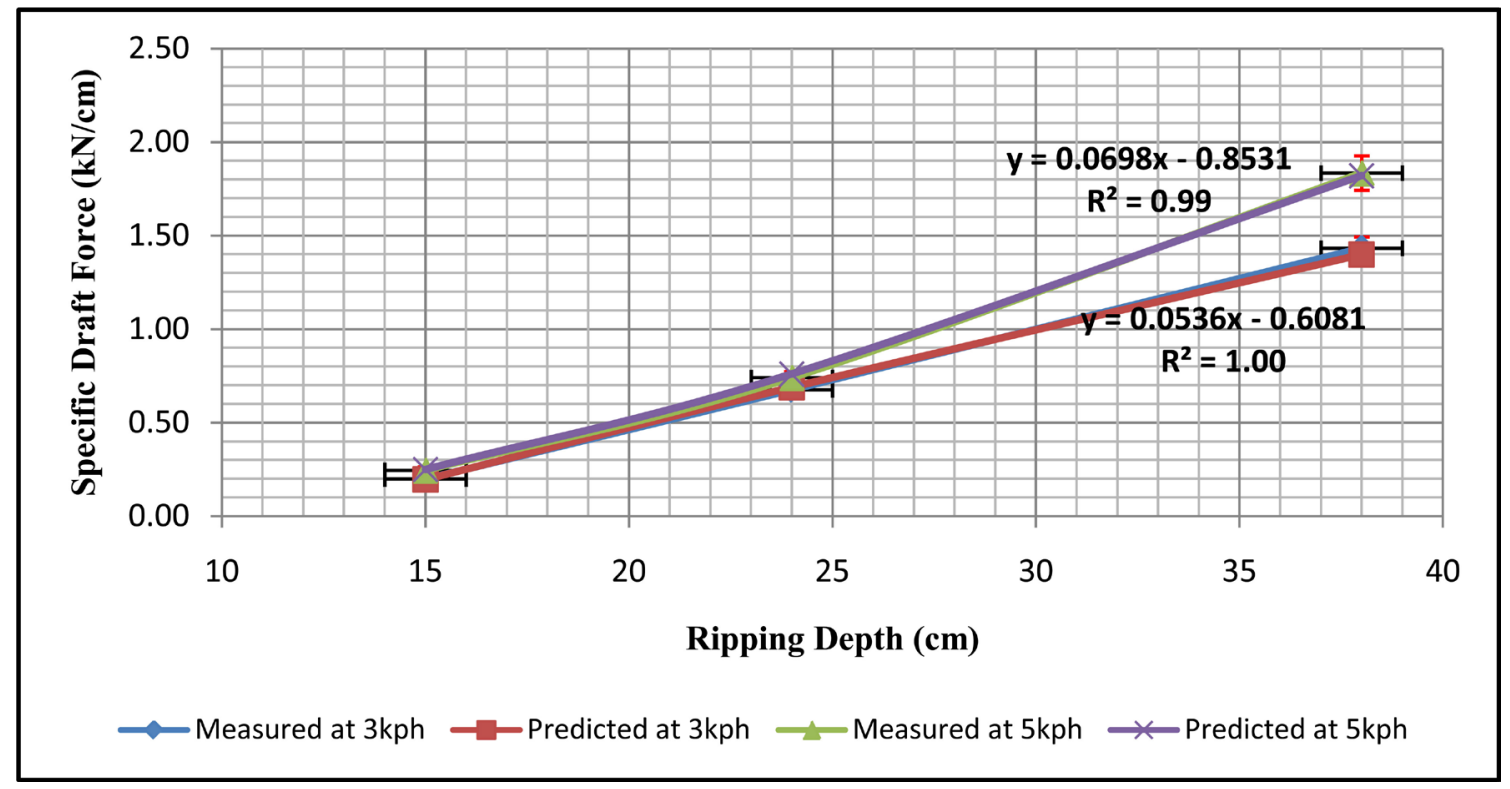

Figure 11. Specific draft force against ripping depth at a rake angle of $45^{\circ}$.

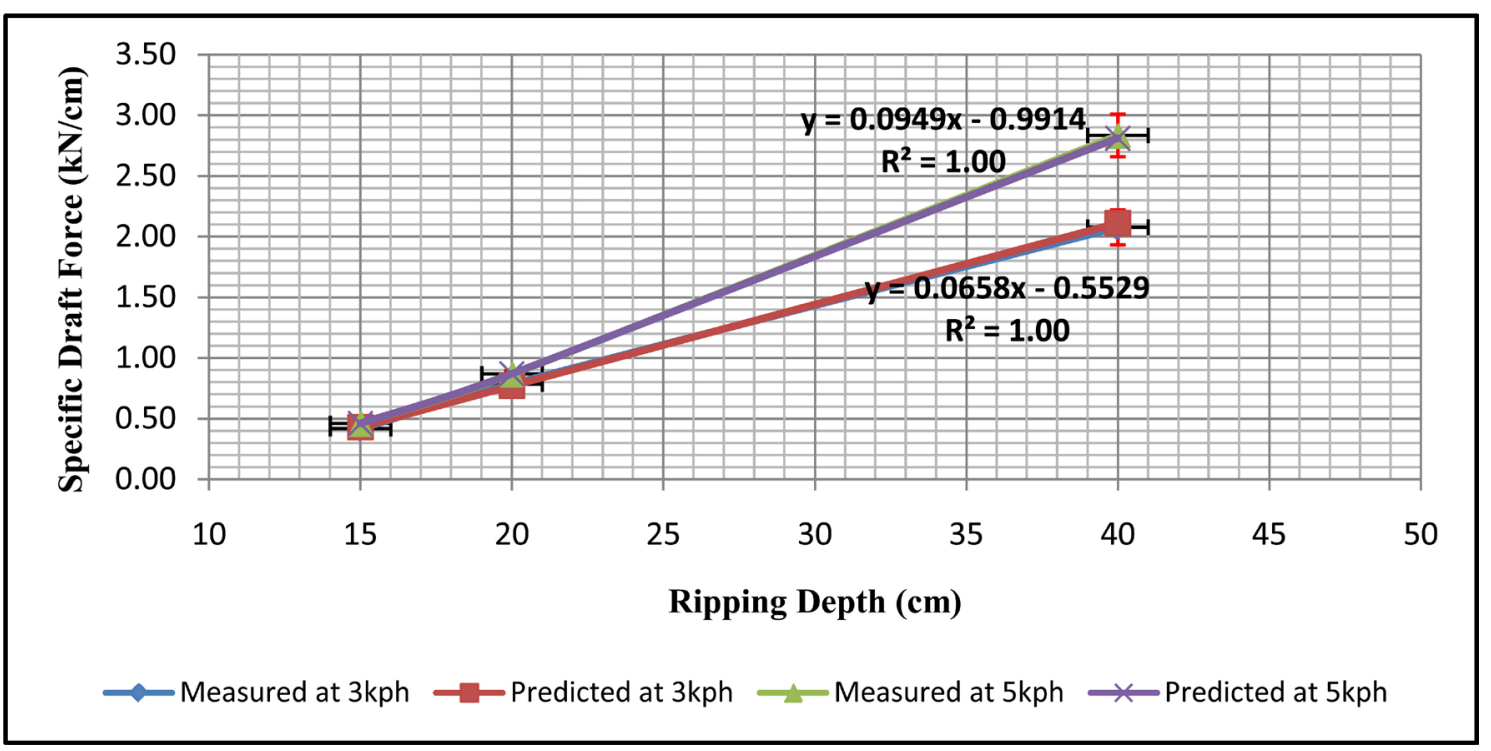

Figure 12. Specific draft force against ripping depth at a rake angle of $60^{\circ}$. 


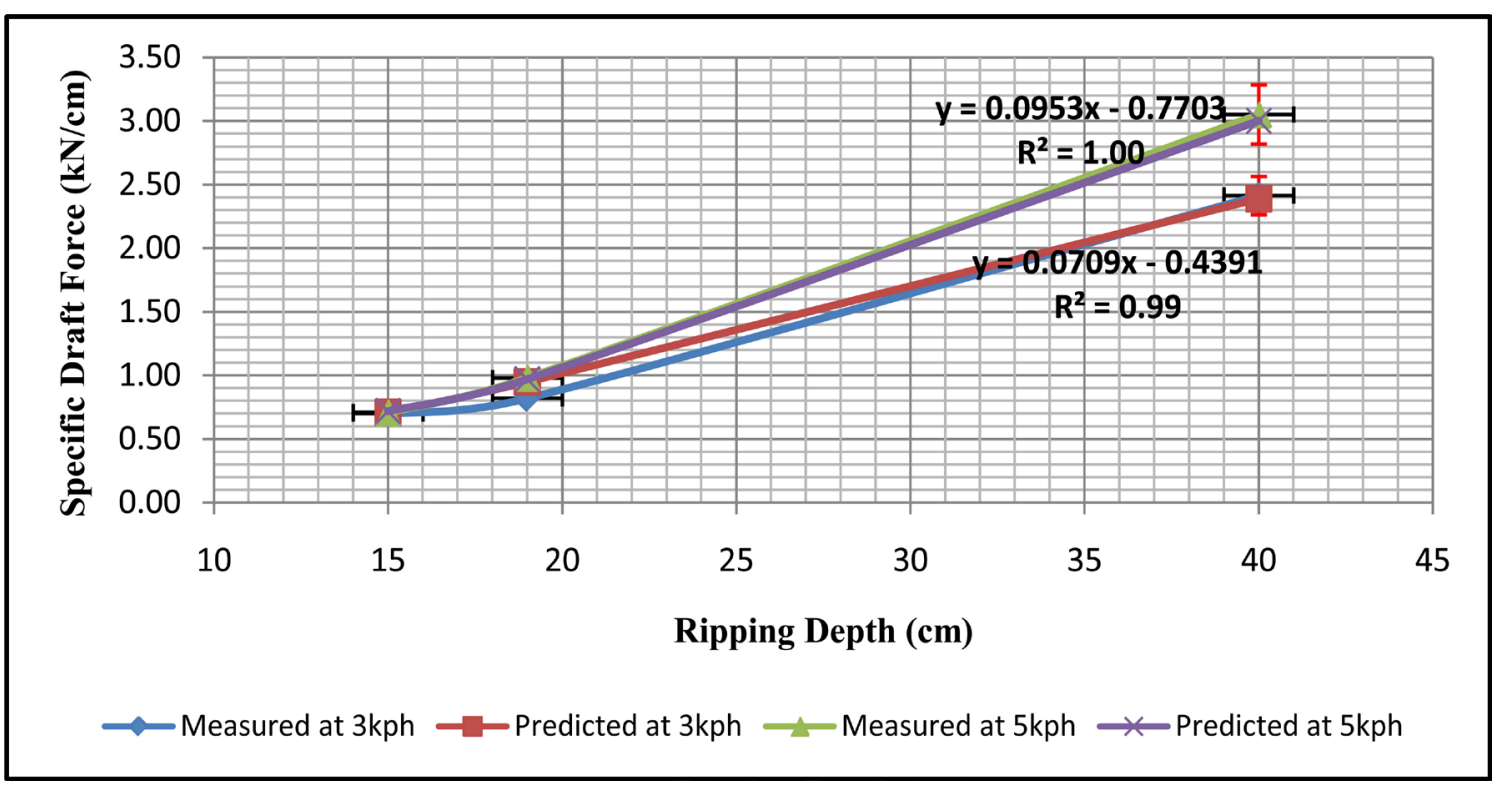

Figure 13. Specific draft force against ripping depth at a rake angle of $75^{\circ}$.

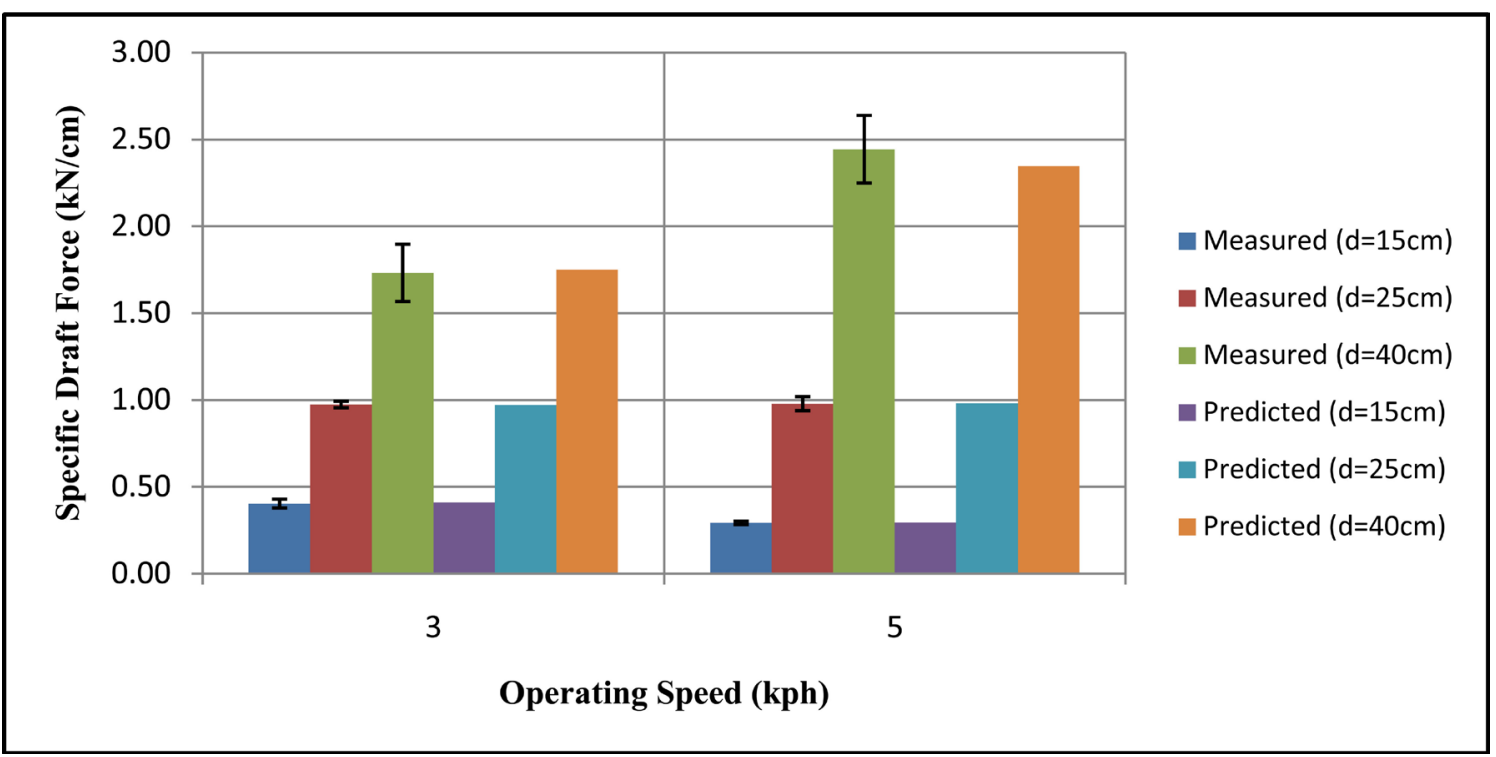

Figure 14. Specific draft force against operating speed at a rake angle of $30^{\circ}$.

reported a linear increase in the draft obtained using the [7] model; they however obtained an exponential increase with the models developed by [8] and [9].

\subsubsection{Effect of Operational Speed}

The effect of the operating speed on the draft has been investigated by various researchers [1] [4] [5] [10] [11]. The general observation has been that increasing the operating speed results to an increase in the draft. [1] however reported that the effect of changing the operating speed on the draft is less pronounced than the effect of changing the working depth on the draft.

Investigations at the rake angle of 30 degrees, as described in Figure 14, revealed that the effect of the change in operating speed on the draft was more prominent at the ripping depth of $40 \mathrm{~cm}$ than at the other depths. This could be due the presence of a loose soil layer at lower ripping depths as discussed in Section 3.5.1.

At the rake angle of 45 degrees, the effect of the change in operating speed on the draft was again more 
prominent at the ripping depth of $40 \mathrm{~cm}$ than at the other depths. At ripping depths less than $40 \mathrm{~cm}$, the change in operating speed resulted to a marginal change in the draft. This is shown in Figure 15.

At the rake angle of 60 degrees, the effect of the change in operating speed on the draft was again more prominent at the ripping depth of $40 \mathrm{~cm}$ than at the other depths as shown in Figure 16. At ripping depths less than $40 \mathrm{~cm}$, the change in operating speed resulted to a marginal change in the draft.

At the rake angle of 75 degrees, the effect of the change in operating speed on the draft was again more prominent at the ripping depth of $40 \mathrm{~cm}$ than at the other depths as shown in Figure 17. At ripping depths less than $40 \mathrm{~cm}$, the change in operating speed resulted to a marginal change in the draft.

\section{Conclusions}

This study aimed at investigating effect of operational parameters (i.e. ripping depth and operating speed) on the

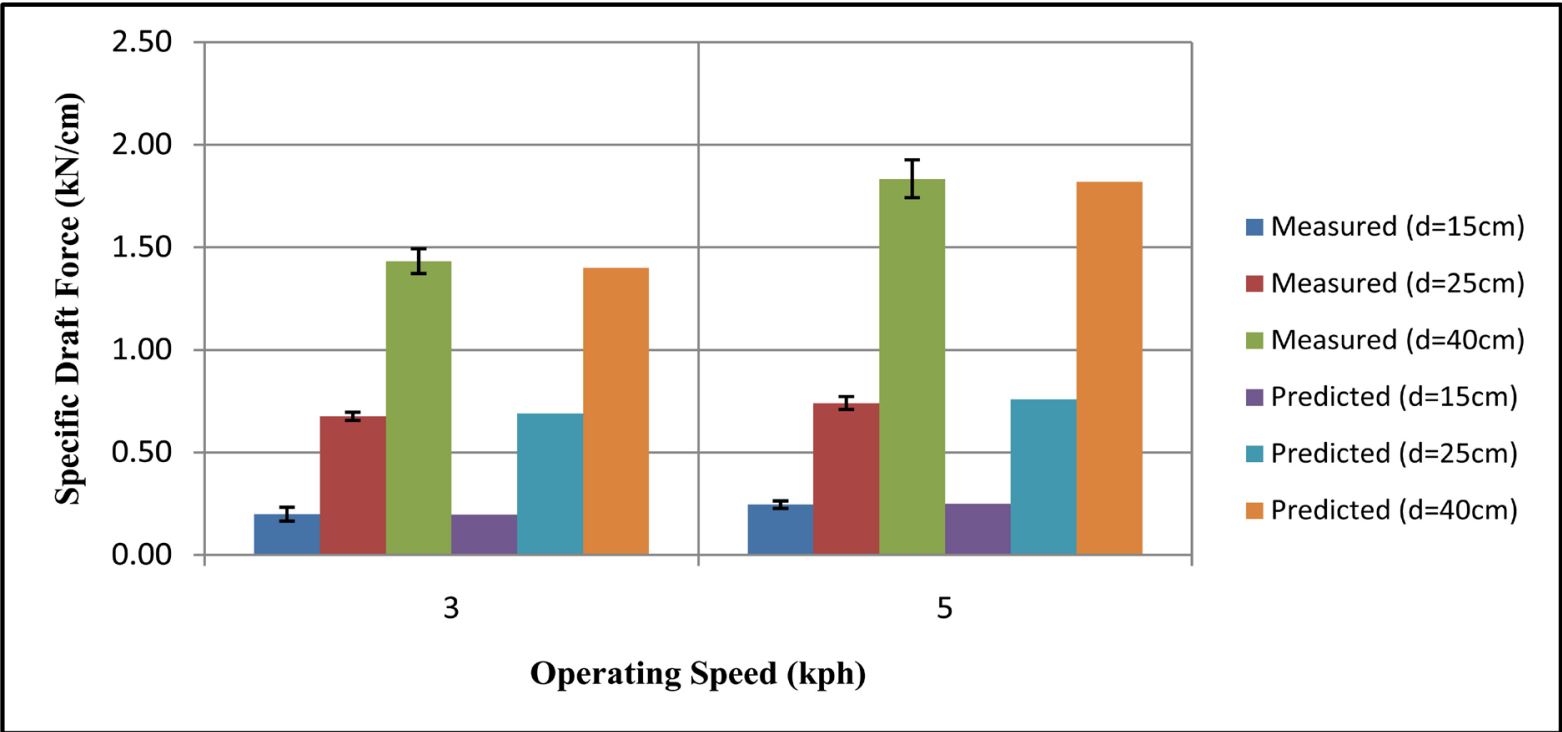

Figure 15. Specific draft force against operating speed at a rake angle of $45^{\circ}$.

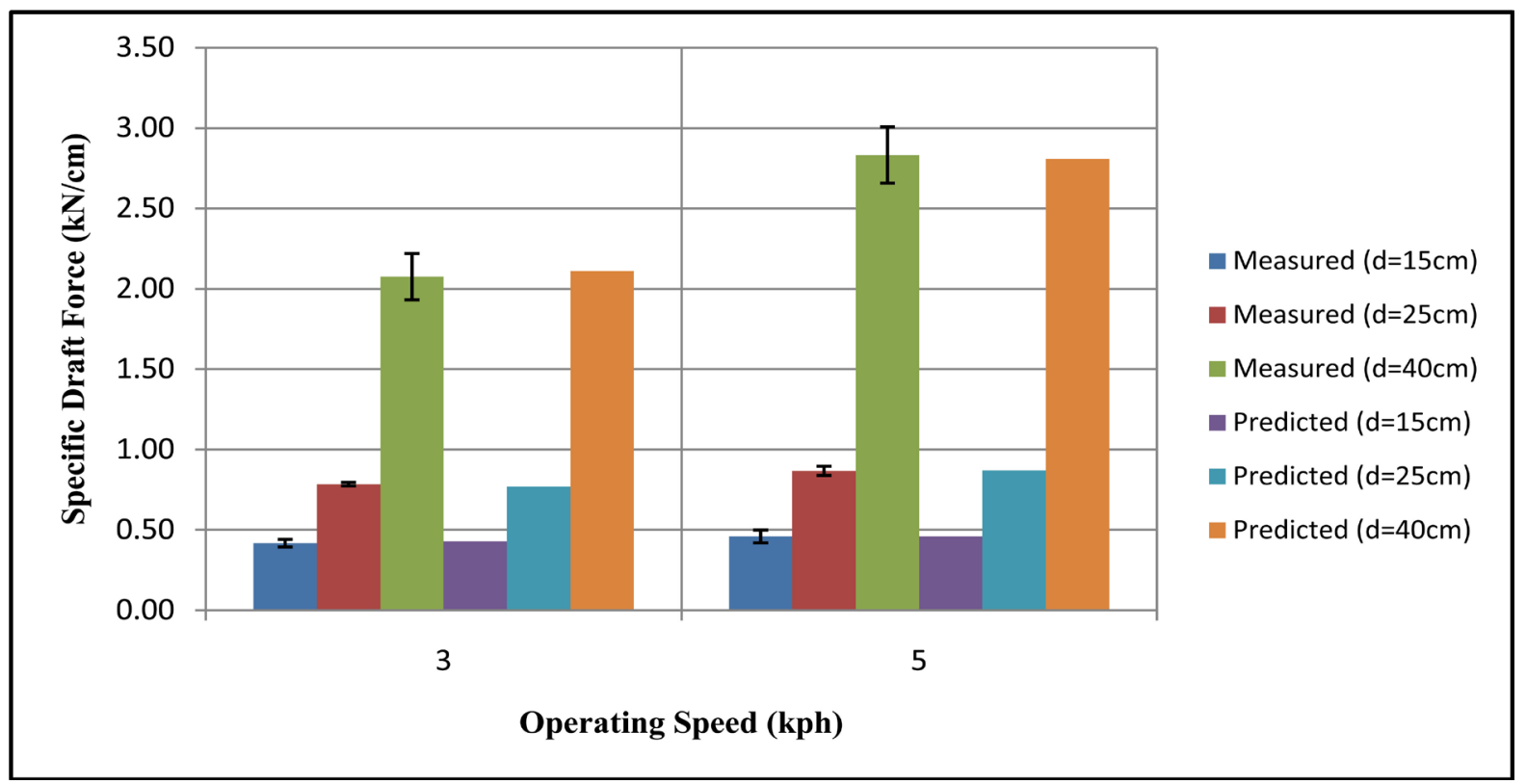

Figure 16. Specific draft force against operating speed at a rake angle of $60^{\circ}$. 


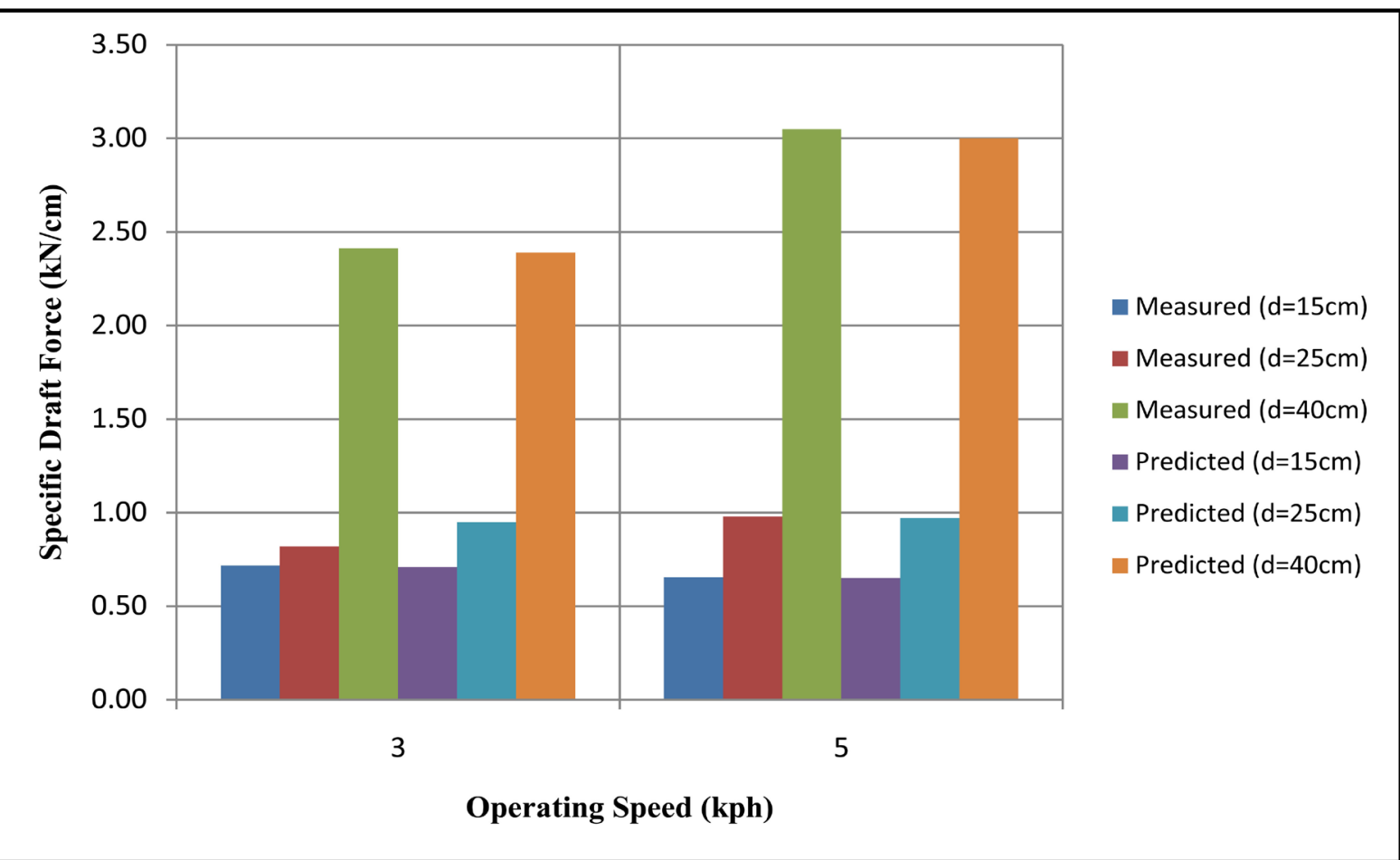

Figure 17. Specific draft force against operating speed at a rake angle of $75^{\circ}$.

draft requirement of ripping in a sandy-clay soil; the information gained can be used to support research initiatives in tillage operations, to guide in the design of better tools and to aid managers of farm machinery in selecting the optimal ripping parameters.

A numerical model was developed with the EDEM Academic ${ }^{\mathrm{TM}}$ software and calibrated by simulating the angle of repose test. The results of the study revealed that the ripping depth and the operating speed influenced the draft requirement to ripping in a sandy-clay soil; it was found out that the draft force was directly proportional to the ripping depth and operational speed; as such, the draft force increased with increase in the two parameters.

The critical depth of ripping was found to be at $34 \mathrm{~cm}$; as such, the draft force was found to be more sensitive to the tillage depth past the $34 \mathrm{~cm}$ level since it was found to increase exponentially past that level. Only two speed levels ( $3 \mathrm{~km} / \mathrm{hr}$ and $5 \mathrm{~km} / \mathrm{hr}$ ) were used in this study; the draft was not sensitive to the changes in speed level; further studies are recommended at finer speed level within the above range to make good observations on their effect on the draft force; however, most tillage operations are conducted within the range of $3 \mathrm{~km} / \mathrm{hr}(0.8$ $\mathrm{m} / \mathrm{s})$ and $5 \mathrm{~km} / \mathrm{hr}(1.4 \mathrm{~m} / \mathrm{s})$ and as such, this study's observations at such a range are usable.

\section{Acknowledgements}

This research was conducted with the sponsorship of the University of Nairobi; the authors would also like to thank DEM Solutions Limited for providing the EDEM Academic ${ }^{\mathrm{TM}}$ software and technical support.

\section{References}

[1] Wiebe, K. (2003) Land Quality, Agricultural Productivity, and Food Security: Biophysical Processes and Economic Choices at Local, Regional, and Global Levels (Google eBook). Edward Elgar Publishing. http://books.google.com/books?id=lZV4lU1fFAgC\&pgis=1

[2] Linde, J. (2007) Discrete Element Modeling of a Vibratory Subsoiler. University of Stellenbosch.

[3] Karuku, G., Gachene, C., Karanja, N., Cornelis, W., Verplancke, H. and Kironchi, G. (2012) Soil Hydraulic Properties of a Nitisol in Kabete Kenya. Tropical and Subtropical Agroecosystems, 15, 595-609.

[4] Sahu, R.K. and Raheman, H.Ã. (2006) Draught Prediction of Agricultural Implements Using Reference Tillage Tools 
in Sandy Clay Loam Soil. Biosystems Engineering, 94, 275-284. http://dx.doi.org/10.1016/j.biosystemseng.2006.01.015

[5] Aboukarima, W. (2007) Draft Models of Chisel Plow Based on Simulation Using Artificial Neural Networks. Misr Journal of Agricultural Engineering, 24, 42-61.

[6] Grisso, R.D. and Perumpral, J.V. (1985) Review of Models for Predicting Performance of Narrow Tillage Tool, 7.

[7] Hettiaratchi, D.R. and Reece, A. (1967) Symmetrical Three-Dimensional Soil Failure. Journal of Terramechanics, 4, 45-67. http://dx.doi.org/10.1016/0022-4898(67)90126-7

[8] Godwin, R.J. and Spoor, G. (1977) Soil Failure with Narrow Tines. Journal of Agricultural Engineering, 22, $213-228$. http://dx.doi.org/10.1016/0021-8634(77)90044-0

[9] McKyes, E. and Ali, O. (1977) The Cutting of Soil by Narrow Blades. Journal of Terramechanics, 14, 43-58. http://dx.doi.org/10.1016/0022-4898(77)90001-5

[10] Ghaly, A. and Al-Suhaibani, S. (2010) Effect of Plowing Depth of Tillage and Forward Speed on the Performance of a Medium Size Chisel Plow Operating in a Sandy Soil. American Journal of Agricultural and Biological Sciences, 5, 247-255. http://dx.doi.org/10.3844/ajabssp.2010.247.255

[11] Moeenifar, A., Seyedi, S.R. and Kalantari, D. (2013) Determination of Traction Force Acting on a Wide Blade Using Dimensional Analysis Method. IJACS, 5, 1403-1409. 